\title{
STAR-CCM+ Verification and Validation Plan
}

W. David Pointer

Oak Ridge National Laboratory

September 30, 2016
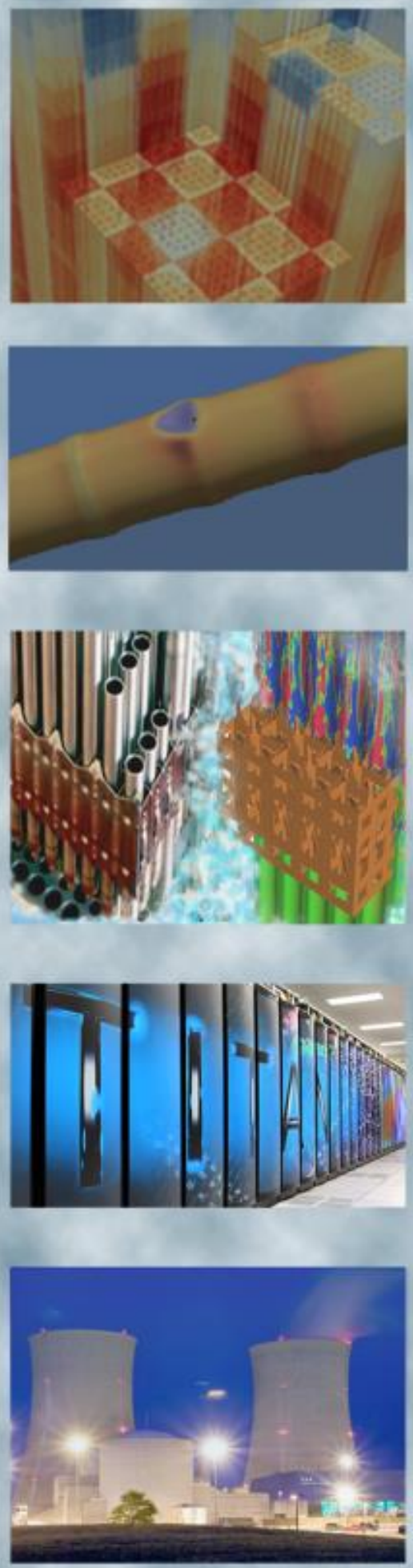
REVISION LOG

\begin{tabular}{|c|c|c|l|}
\hline Revision & Date & Affected Pages & \multicolumn{1}{c|}{ Revision Description } \\
\hline 0 & $09 / 30 / 2016$ & All & Initial Release \\
\hline & & & \\
\hline & & & \\
\hline & & & \\
\hline
\end{tabular}

\section{Document pages that are:}

Export Controlled None

IP/Proprietary/NDA Controlled None

Sensitive Controlled None

This report was prepared as an account of work sponsored by an agency of the United States Government. Neither the United States Government nor any agency thereof, nor any of their employees, makes any warranty, express or implied, or assumes any legal liability or responsibility for the accuracy, completeness, or usefulness of any information, apparatus, product, or process disclosed, or represents that its use would not infringe privately owned rights. Reference herein to any specific commercial product, process, or service by trade name, trademark, manufacturer, or otherwise, does not necessarily constitute or imply its endorsement, recommendation, or favoring by the United States Government or any agency thereof. The views and opinions of authors expressed herein do not necessarily state or reflect those of the United States Government or any agency thereof.

\section{Requested Distribution:}

To: THM roster

Copy: SLT

Approved for public release. Distribution is unlimited. 


\section{EXECUTIVE SUMMARY}

The commercial Computational Fluid Dynamics (CFD) code STAR-CCM+ provides general purpose finite volume method solutions for fluid dynamics and energy transport. This document defines plans for verification and validation $(\mathrm{V} \& \mathrm{~V})$ of the base code and models implemented within the code by the Consortium for Advanced Simulation of Light Water Reactors (CASL). The software quality assurance activities described herein are part of the overall software life cycle defined in the CASL Software Quality Assurance (SQA) Plan [Sieger 2015].

STAR-CCM+ serves as the principal foundation for development of an advanced predictive multiphase boiling simulation capability within CASL. The CASL Thermal Hydraulics Methods (THM) team develops advanced closure models required to describe the subgrid-resolution behavior of secondary fluids or fluid phases in multiphase boiling flows within the Eulerian-Eulerian framework of the code. These include wall heat partitioning models that describe the formation of vapor on the surface and the forces that define bubble/droplet dynamic motion. The CASL models are implemented as user coding or field functions within the general framework of the code.

This report defines procedures and requirements for $V \& V$ of the multi-phase CFD capability developed by the CASL THM team. Results of V\&V evaluations will be documented in a separate STAR-CCM+ V\&V assessment report. This report is expected to be a living document and will be updated as additional validation cases are identified and adopted as part of the CASL THM V\&V suite. 


\section{CONTENTS}

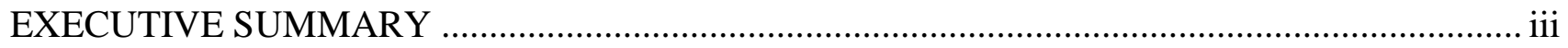

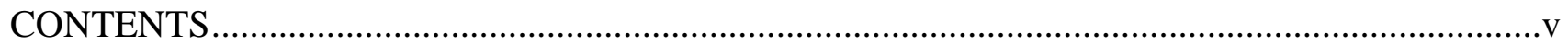

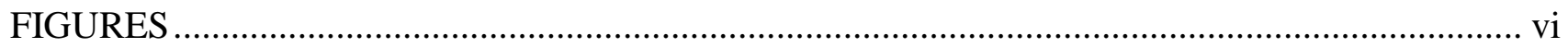

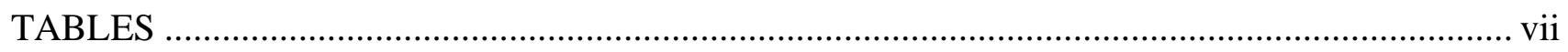

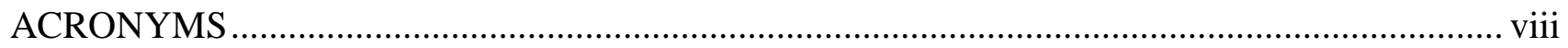

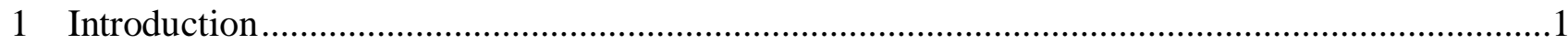

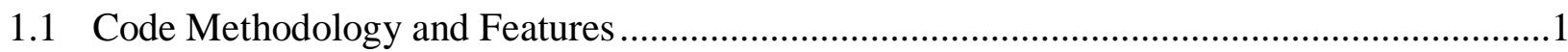

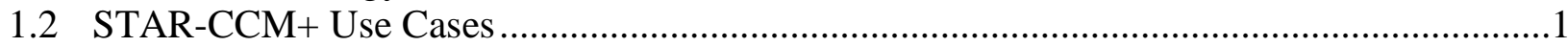

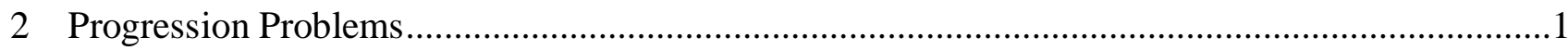

3 Code Quality Assurance ……………..............................................................................

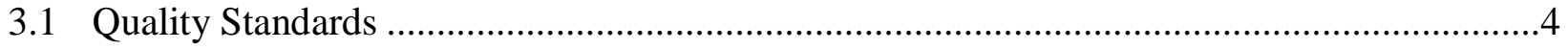

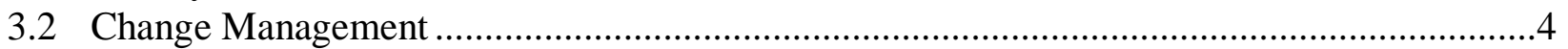

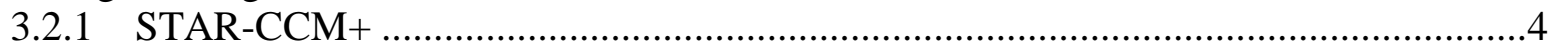

3.2.2 CASL THM User Coding and Field Functions .............................................................

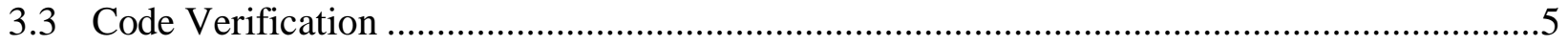

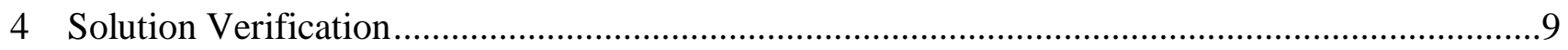

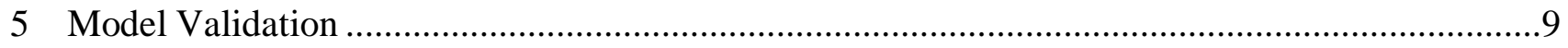

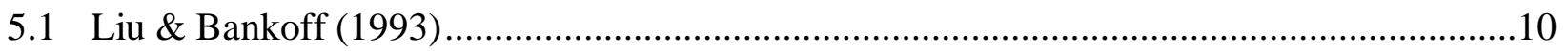

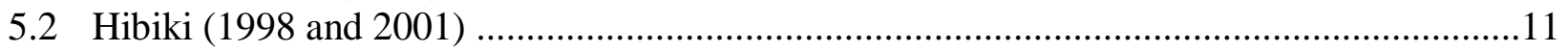

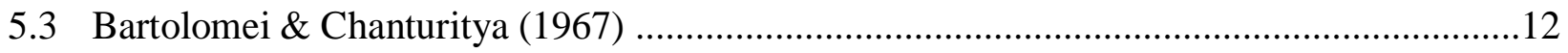

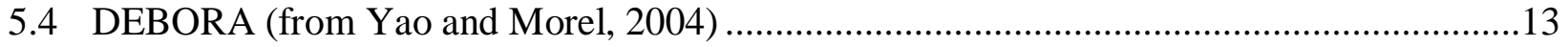

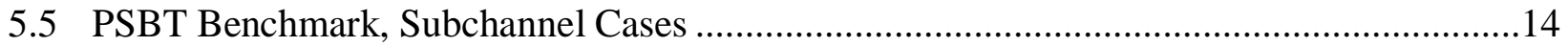

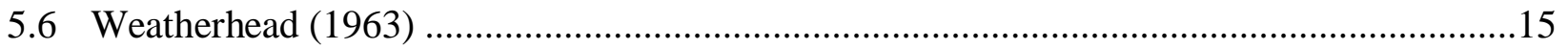

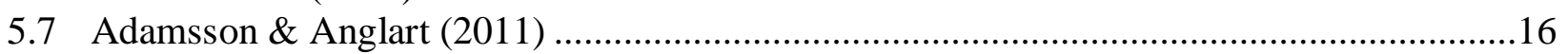

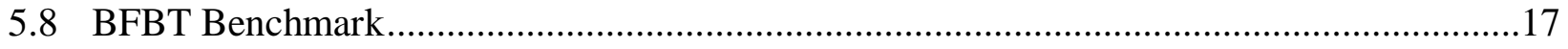

5.9 V\&V Assessment Reporting ..................................................................................

6 Additional Codes Developed or Used by CASL THM ............................................................18

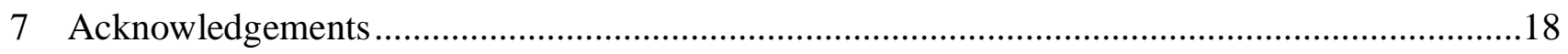

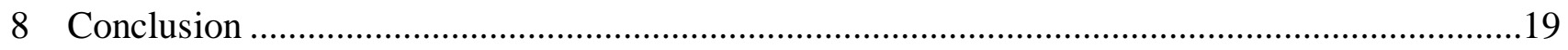




\section{FIGURES}

Figure 2-1. Notional View of Development Activity Relationships to CASL Challenge Problems.... 2

Figure 5-1. Channel Characteristics for Liu \& Bankoff Validation Cases. ..................................... 10

Figure 5-2. Channel Characteristics for Hibiki Validation Cases............................................... 11

Figure 5-3. Channel Characteristics for Bartolomei \& Chanturitya Validation Cases..................... 12

Figure 5-4. Channel Characteristics for DEBORA Validation Cases. .......................................... 13

Figure 5-5. Channel characteristics for PSBT validation cases. ............................................... 14

Figure 5-6. Channel Characteristics for Weatherhead Validation Cases...................................... 15

Figure 5-7. Channel Characteristics for Adamsson \& Anglart Validation Cases............................. 16

Figure 5-8. Channel Characteristics for BFBT Validation Cases............................................... 17

Figure 5-9. Radial Power Profile for BFBT Validation Cases. ................................................... 17 


\section{TABLES}

Table 2-1. Single Phase Isothermal Progression Problems. .......................................................... 2

Table 2-2. Single Phase Heat Transfer Progression Problems. ....................................................... 3

Table 2-3. Two Phase Flow Progression Problems. .................................................................. 3

Table 3-1. Summary of cases included in STAR-CCM+ Customer Verification Suite. .................... 7

Table 5-1. Summary of validation cases by geometry and flow regime. .................................... 9 


\section{ACRONYMS}

$\begin{array}{ll}\text { ALM } & \text { application lifecycle management } \\ \text { ANSI } & \text { American National Standards Institute } \\ \text { ASME } & \text { American Society of Mechanical Engineers } \\ \text { BFBT } & \text { boiling water reactor full-height bundle test } \\ \text { BWR } & \text { boiling water reactor } \\ \text { CASL } & \text { Consortium for Advanced Simulation of Light Water Reactors } \\ \text { CILC } & \text { crud induced local corrosion } \\ \text { CFD } & \text { computational fluid dynamics } \\ \text { DEBORA } & \text { experimental facility name (not an acronym) } \\ \text { DNB } & \text { departure from nucleate boiling } \\ \text { DOE } & \text { US Department of Energy } \\ \text { NRC } & \text { US Nuclear Regulatory Commission } \\ \text { NQA-1 } & \text { Nuclear Quality Assurance Standard 1 } \\ \text { PIRT } & \text { phenomena ranking and identification table } \\ \text { PSBT } & \text { pressurized water reactor subchannel and bundle test } \\ \text { PWR } & \text { pressurized water reactor } \\ \text { RANS } & \text { Reynolds Averaged Navier-Stokes } \\ \text { SLT } & \text { senior leadership team } \\ \text { STAR-CCM+ commercial CFD code name (not an acronym) } & \text { software quality assurance } \\ \text { SQA } & \text { Semi-Implicit Method for Pressure-Linked Equations } \\ \text { SIMPLE } & \text { Thermal Hydraulics Methods (team) } \\ \text { THM } & \text { verification and validation } \\ \text { V\&V } & \end{array}$




\section{INTRODUCTION}

The commercial computational fluid dynamics (CFD) code STAR-CCM+, developed by CDadapco, provides general purpose finite volume method solutions for fluid dynamics and energy transport. This document defines plans for verification and validation (V\&V) of the base code and models implemented within the code by the Consortium for Advanced Simulation of Light Water Reactors (CASL). The software quality assurance (SQA) activities described herein are part of the overall software life cycle defined in the SQA Plan [Sieger, 2015].

This report defines procedures and requirements for $V \& V$ of the multi-phase CFD capability developed by the CASL Thermal Hydraulics Methods (THM) team. Results of V\&V evaluations will be documented in a separate STAR-CCM+ V\&V assessment report. This report is expected to be a living document and will be updated as additional validation cases are identified and adopted as part of the CASL THM V\&V suite.

\subsection{Code Methodology and Features}

The commercial CFD code STAR-CCM+, developed by CD-adapco and used under license by CASL partners, serves as the principal foundation for development of an advanced predictive multiphase boiling simulation capability within CASL. STAR-CCM+ provides a finite volume method fluid dynamics solution using the common Semi-Implicit Method for Pressure-Linked Equations (SIMPLE) with Rhie-Chow interpolation for pressure-velocity coupling and algebraic multi-grid preconditioning. The code provides a variety of Reynolds Averaged Navier-Stokes (RANS) turbulence modeling options and supports large eddy simulations. Second order accurate differencing schemes are generally applied in both space in time.

STAR-CCM+ offers several multiphase flow simulation options, including mixture modelling, volume of fluid methods, and a Eulerian-Eulerian dispersed phase capability. The CASL THM team develops advanced closure models required to describe the subgrid-resolution behavior of secondary fluids or fluid phases in multiphase boiling flows within the Eulerian-Eulerian framework of the code. These include wall heat partitioning models that describe the formation of vapor on the surface, and the forces that define bubble/droplet dynamic motion. CASL models are implemented as user coding or field functions within the general framework of the code.

\subsection{STAR-CCM+ Use Cases}

The advanced Eulerian-Eulerian multiphase boiling flow capability implemented in STAR-CCM+ is used in support of two CASL challenge problems: the prediction of crud induced localized corrosion (CILC) in pressurized water reactor (PWR) fuel assemblies and the prediction of departure from nucleate boiling (DNB) in PWR fuel assemblies. It is also the predictor of conditions in boiling water reactors (BWRs). Important phenomena for the prediction of CILC and DNB have been identified in phenomena ranking and identification tables (PIRTs) in the CASL V\&V Plan [Mousseau and Dinh 2016]. These problems drive software development, as illustrated in Figure 2-1.

\section{PROGRESSION PROBLEMS}

A series of thermal hydraulics progression problems have been defined to help guide the development of the advanced boiling models and aid the THM team in assessing development progress. THM progression problems for single phase flow and heat transfer are defined in Table 2-1 and Table 2-2. Problem details have been defined by Smith, et al., in 2015. Similar cases are already included in the STAR-CCM+ test suite. These cases are included here for completeness but are unlikely to be tested explicitly in CASL. The two phase flow and heat transfer cases that are the primary focus of CASL THM are defined in 
Table 2-3. Specific test cases are being developed as methodolgy is defined.

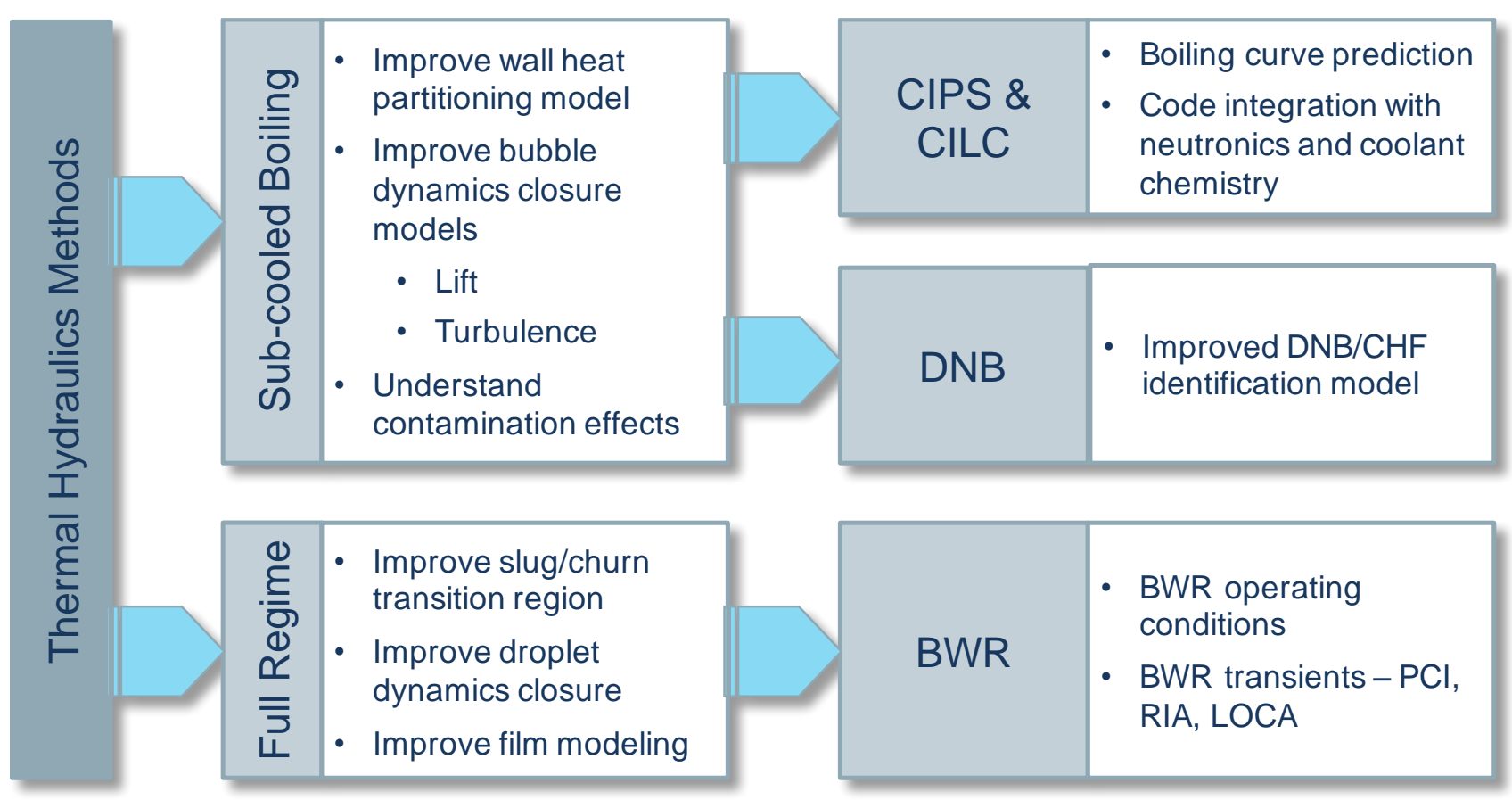

Figure 2-1. Notional view of development activity relationships to CASL challenge problems.

Table 2-1. Single phase isothermal progression problems.

\begin{tabular}{ll}
\hline Test & Objectives \\
\hline Back step & Reattachment \\
Channel & Law-of-wall \\
Grid turbulence & Decay rate \\
Couette flow & Mean velocity profiles \\
Mixing layer & Scale similarity \\
Jets & Spreading rate \\
Pipe flow & Law-of-wall, Nu \\
J-channel & Curvature effects \\
Circular cylinder in crossflow & Strouhal No. \\
Asym. diffuser & Separation \\
Impinging jet & Stagnation point \\
Jet in crossflow & Complex vortex \\
\hline
\end{tabular}


Table 2-2. Single phase heat transfer progression problems.

\begin{tabular}{ll}
\hline \multicolumn{1}{c}{ Test } & \multicolumn{1}{c}{ Objectives } \\
\hline Turbulent channel & Law-of-wall \\
Turbulent pipe flow & Temperature profile \\
J-channel & Curvature effects \\
Circular cylinder in crossflow & Crossflow heat transfer \\
Sub-channel & Secondary flow effects \\
Bundle/spacer segment & Secondary flow effects \\
\hline
\end{tabular}

Table 2-3. Two phase flow progression problems.

\begin{tabular}{ll}
\hline \multicolumn{1}{c}{ Test } & \multicolumn{1}{c}{ Objectives } \\
\hline Vertical pipe & Lam. air/water bubbly flow \\
Vertical pipe & Turb. air/water bubbly flow \\
Vertical annulus & Lam. air/water bubbly flow \\
Vertical annulus & Turb. air/water bubbly flow \\
Vertical pipe & Laminar subcooled boiling \\
Vertical pipe & Turb. subcooled boiling \\
Vertical annulus & Laminar subcooled boiling \\
Vertical annulus & Turb. subcooled boiling \\
Sub-channel & Subcooled boiling secondary flow effects \\
Bundle/spacer segment & Subcooled boiling secondary flow effects \\
Vertical pipe & Lam. slug/churn two-phase \\
Vertical pipe & Turb. slug/churn two-phase \\
Vertical annulus & Lam. slug/churn two-phase \\
Vertical annulus & Turb. slug/churn two-phase \\
Sub-channel & Slug/churn secondary flow effects \\
Bundle/spacer segment & Slug/churn secondary flow effects \\
Vertical pipe & Lam. annular two-phase \\
Vertical pipe & Turb. annular two-phase \\
Vertical annulus & Lam. annular two-phase \\
Vertical annulus & Turb. annular two-phase \\
Sub-channel & Annular secondary flow effects \\
Bundle/spacer segment & Annular secondary flow effects \\
\hline
\end{tabular}




\section{CODE QUALITY ASSURANCE}

\subsection{Quality Standards}

STAR-CCM+ has historically been developed using an ISO9001 certified quality assurance process. More recently, $\mathrm{CD}$-adpaco has begun to pursue commercial grade dedication for the code under the US Nuclear Regulatory Commission (NRC). A baseline is being developed which is compliant with the Nuclear Quality Assurance-1 (NQA-1) certification of the American Society of Mechanical Engineers (ASME). In of September 2016, a readiness review was successfully completed by CDadapco, but the commercial grade dedication process continues. CASL is leveraging many improvements implemented as a consequence of the commercial grade dedication effort.

In addition to detailed user and methodology documentation, CD-adapco maintains a quality assurance manual which defines a continuous delivery strategy for the STAR-CCM+ code. The manual requires development of a project plan for each code change, including a clear test plan for code verification and definition of acceptance criteria. Among other data, project plans must identify:

- Related user/ methodology documentation

- Reference materials

- Test case descriptions

- Meshes and geometries

- Physical setup and boundary conditions

- Test data

- Limitations and risks

- Requirements

- Milestones

- Acceptance criteria

\subsection{Change Management}

\subsubsection{STAR-CCM+}

The STAR-CCM+ source code is maintained in a software repository which provides change tracking and version management. All development activities are planned, tracked, and assessed in the CD-adapco Application Lifecycle Management (ALM) system.

\subsubsection{CASL THM User Coding and Field Functions}

The models developed by the CASL THM team are implemented in STAR-CCM+ via user coding and field functions. The user coding functions are $\mathrm{C}$ or Fortran code which can be compiled with STAR-CCM+ and used to replace entire code features such as a lift force model in Eulerian-Eulerian models of multi-phase boiling flows. The field functions are java functions which can be used to define parameters in existing models or user coding.

Through the end of fiscal year 2016, user coding and field functions have been considered developmental, and version control has been left to individual users and developers. With the completion of a reasonably robust baseline in fiscal year 2016, more aggressive testing by the broader team will begin in fiscal year 2017. In preparation for this shift in prioritization, a more rigorous centralized change management system will be established in early 2017 based on the existing CASL repository and activity tracking systems. 


\subsection{Code Verification}

Within CD-adapco, code verification cases are implemented with the STAR-TEST suite, which includes more than 30,000 individual test cases with baseline data stored in the internal data warehouse. The database includes both unit tests and application verification tests that may be based on standard validation problems. A fraction of all tests is automatically executed weekly, with results reported through the Application Lifecycle Management (ALM) system. All tests are executed before code releases.

A subset of the STAR-Test suite is distributed with the code as a customer verification suite. Although principally intended for confirmation of new local installations, the suite of 77 cases includes some cases relevant to the CASL THM development efforts and will serve as a baseline verification suite while more specific verification cases are being defined. The cases making up the customer verification suite are highlighted in 
Table 3-1.

CASL specific verification cases will be defined as closure models are developed. 


\section{Table 3-1. Summary of cases included in STAR-CCM+ customer verification suite.}

\section{Aeroacoustics}

- Noise emission from coaxial jets

- Propagation of a planar acoustic wave

- flow and energy

- Natural convection in an eccentric annulus

- Flow through an asymmetric plane diffuser

- Lid-driven flow in a twodimensional square cavity

- Counter-flow heat exchanger in a two-dimensional channel modeled with periodic heat transfer

- Porous dominated flow

- "Darcy's law" in one-dimensional incompressible flow using porous media

- Natural convection in a laminar square cavity with large temperature difference

- Karman vortex shedding

- Porous dominated swirling flow in an annulus

- $\quad$ Porous baffle

- Unsteady conduction heat transfer through a solid slab

- $\quad$ Non-Newtonian generalized Carreau-Yasuda flow in an axisymmetric pipe

- Natural convection between two infinite vertical walls

- Laminar high-capacity heat exchanger modeled with fullydeveloped energy

- Enthalpy source to mimic a heat exchanger

- Laminar flow of a viscoelastic fluid in cross flow

- $\quad$ Flow of viscoelastic fluid past a cylinder

Time

- $\quad$ Stokes' first problem: the suddenly accelerated wall

\section{Radiation}

- $\quad$ Radiative heat transfer in scattering media using the discrete ordinate method

- $\quad$ Surface-to-surface radiation in an empty rectangular box

- $\quad$ Surface-to-surface radiation in a cylindrical hole

- $\quad$ Surface-to-surface radiation in a hollow cylinder
- $\quad$ Surface-to-surface radiation heat transfer reduction across a single shield

- $\quad$ Gray thermal radiation using a hexahedral mesh

\section{Combustion}

- Sandia piloted ch4/air jet flame d

- Turbulent lifted hydrogen flame

- Propane and air in a v-shaped combustor

LaGrangian multiphase

- Evaporation of multi-component droplets in dry air

- Turbulent dispersion of material particles in grid-generated turbulence

\section{Eulerian multiphase}

- Aeration tank with impermeable boundary for continuous water phase

- Polynomial specific heat for pressurized water

- Wall heat flux condition

- Bulk boiling

- Bozzano-Dente and Tomiyama drag laws

- Particle acceleration by drag

- Bulk boiling using s-gamma size distribution

- $\quad$ Rising terminal velocity of bubbles with drag laws

- Bubble acceleration under virtual mass force

- Tomiyama transverse lift coefficient with air bubbles

- Bubbly flow in water with variable density

- Fluid acceleration as a solid body

- $\quad$ Three phase particle terminal velocity

- Hydrotransport with turbulence

- Hibiki bubble column using sgamma size distribution modeling

- Increase of bubble size due to pressure decrease in an ideal gas

Multiphase volume of fluid

- $\quad$ Free surface flow and heat transfer in a straight channel

- Flow in a capillary pipe

- Overset and non-overset: water impact of a wedge
Solid stress

- Stress analysis of a twodimensional rectangular plate with a hole

- $\quad$ Fluid structure interaction using small displacement theory

- Deformation analysis of an elastic solid due to exerted fluid pressure

Finite element solid stress

- $\quad$ Finite-element bending of a cantilever beam

- $\quad$ Finite-element Scordelis lo roof

Electric potential

- Electric potential in a square domain

\section{Compressible flow}

- One-dimensional shock tube

- Supersonic flow over a flat plate

- Turbulent subsonic flow through an aero intake

- Turbulent transonic flow over an rae-2822 airfoil

- Quasi-1d converging-diverging nozzle flow

- Two-dimensional shock reflection

Turbulence

- Two-dimensional single-hill flows

- Turbulent compressible flow in a two-dimensional convergingdiverging nozzle

- Fully developed turbulent pipe flow

- Turbulent natural convection in a heated cavity of aspect ratio 1

- Turbulent flow over a surfacemounted rib

- Turbulent flow in a channel using a wall-function mesh and a low-re mesh

- Two-dimensional transonic diffuser

- Turbulent flow and heat transfer over a backward-facing step

- Axisymmetric impinging turbulent jet with heat transfer

- T3a transition

- Turbulent flow in a swirling diffuser

- Curved turbulent channel flow

- Transitional boundary layer

- Turbulent natural convection in a heated cavity of aspect ratio 5 


\section{SOLUTION VERIFICATION}

Unique solution verification standards have not been independently defined for the CASL team. The CASL THM team recommends the application of solution verification methods defined in the ASME Guide on Verification and Validation in Computational Fluid Dynamics and Heat Transfer, which was published as the American National Standards Institute (ANSI) V\&V20 standard in 2009.

\section{MODEL VALIDATION}

A series of validation cases have been identified which track with the progression problems. The initial code and closure model validation matrix is summarized in Table 5-1. Key features of each case are summarized in the following sections. Validation assessments should generally follow the guidelines defined in the ASME Guide on Verification and Validation in Computational Fluid Dynamics and Heat Transfer, which was published as the American National Standards Institute (ANSI) V\&V 20 standard in 2009. Limited application of the ANSI V\&V 20 standard guidelines or the application of alternate guidance in lieu of the ANSI V\&V 20 standard should be justified and documented in code $\mathrm{V} \& \mathrm{~V}$ assessment reports.

Table 5-1. Summary of validation cases by geometry and flow regime.

\begin{tabular}{|l|l|l|l|l|} 
& Bubbly flow & $\begin{array}{l}\text { Slug/churn } \\
\text { flow }\end{array}$ & Annular flow & $\begin{array}{l}\text { Departure from } \\
\text { nucleate boiling }\end{array}$ \\
\hline $\begin{array}{l}\text { Pin bundle } \\
\text { geometry }\end{array}$ & BFBT & BFBT & BFBT & Westinghouse $5 \times 5$ \\
\hline $\begin{array}{l}\text { Separate } \\
\text { effects in } \\
\text { simple } \\
\text { geometry }\end{array}$ & Liu and Bankoff & Hibiki & Hibiki & Weatherhead \\
\hline & $\begin{array}{l}\text { Bartolomei } \\
\text { DEBORA }\end{array}$ & & Adamsson & \\
\hline & PSBT (subchannel) & & & \\
\hline
\end{tabular}




\subsection{Liu \& Bankoff (1993)}

- Data source:

- Liu, T. and Bankoff, S. (1993). Structure of air-water bubbly flow in a vertical pipe -1 . liquid mean velocity and turbulence measurements. International Journal of Heat and Mass Transfer, 36(4):1049-1060.

- Related CASL challenge problems

- CRUD, DNB, BWR

- Coolant

- Air injected into water flow

- Flow regime:

- Bubbly

- Dimensions

- $\quad$ Pipe diameter $=0.038 \mathrm{~m}$

- Channel length $=2.8 \mathrm{~m}$

- Conditions

- Adiabatic (283 K)

- $\quad$ System pressure $=$ atmospheric

- Inlet superficial liquid velocity $=0.376$ to $1.391 \mathrm{~m} / \mathrm{s}$

- Inlet superficial gas velocity $=0.027$ to $0.347 \mathrm{~m} / \mathrm{s}$

- Measurements

- Local void fraction

- Liquid velocity

- Turbulent fluctuations

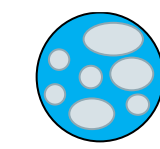

$\mathrm{D}=38.0 \mathrm{~mm}$

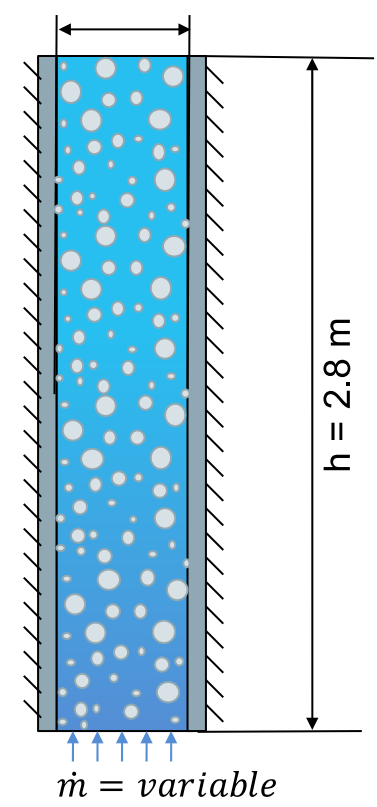

Figure 5-1. Channel characteristics for Liu \& Bankoff validation cases. 


\subsection{Hibiki (1998 and 2001)}

- Data sources:

- Hibiki, Hogsett, and Ishii, "Local measurement of interfacial area, interfacial velocity and liquid turbulence in two-phase flow," Nuclear Engineering and Design 184 (1998) 287-304.

- Hibiki, Ishii and Xiao, "Axial interfacial area transport of vertical bubbly flows," International Journal of Heat and Mass Transfer 44 (2001) 1869-1888.

- Related CASL challenge problems

- CRUD, DNB, BWR

- Coolant

- Air injected into water flow

- Flow Regime

- Bubbly, slug churn, annular

- Dimensions

- Pipe diameter $=0.0508 \mathrm{~m}$

- Channel length $=3.658 \mathrm{~m}$

- Conditions

- Adiabatic (293 K)

- $\quad$ System pressure $=$ atmospheric

- Inlet superficial liquid velocity $=0.491$ to $5.0 \mathrm{~m} / \mathrm{s}$

- Inlet superficial gas velocity $=0.0147$ to $3.9 \mathrm{~m} / \mathrm{s}$

- Inlet void fraction $=0.0130$ to 0.442

- Data

- LOCAL void fraction

- INTERFACIAL area concentration

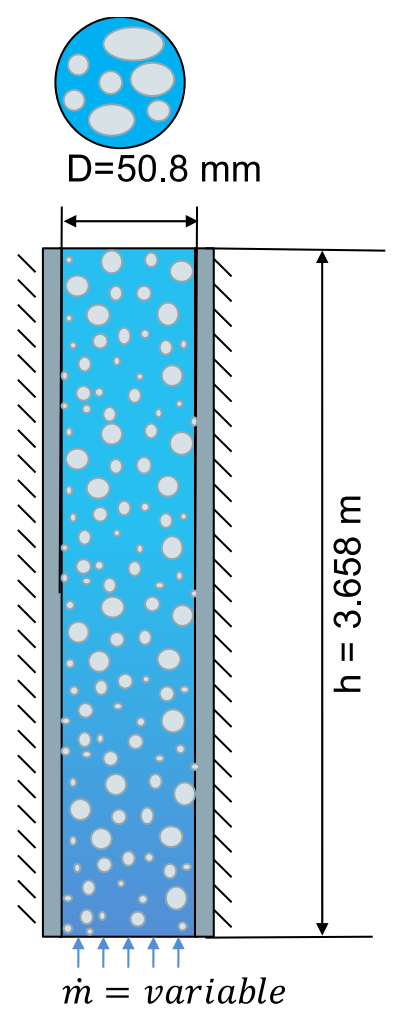

Figure 5-2. Channel characteristics for Hibiki validation cases.

- INTERFACIAL velocity,

- Sauter mean diameter

- LIQUID velocity

- TURBULENT intensity 


\subsection{Bartolomei \& Chanturitya (1967)}

- Data source:

- G. G. Bartolomei and V. M. Chanturiya, "Experimental study of true void fraction when boiling subcooled water in vertical tubes," Thermal Engineering 14, 1967, 123-128, translated from Teploenergetika 14, 1967, 80-83.

- $\quad$ Related CASL challenge problems

- CRUD, DNB, BWR

- Coolant

- Boiling water

- Flow Regime

- Bubbly

- Dimensions

- Pipe diameter $=0.0154 \mathrm{~m}$

- Channel length $=2 \mathrm{~m}$

- Conditions

- Wall heat flux $=0.57 \mathrm{MW} / \mathrm{m}^{2}$

- System pressure $=4.5 \mathrm{MPa}$

- Inlet mass flux $=900 \mathrm{~kg} / \mathrm{m}^{2} \mathrm{~s}$

- Inlet subcooling $=60 \mathrm{~K}$

- Data

- Void profile

- Wall temperature profile

- Bulk temperature profile

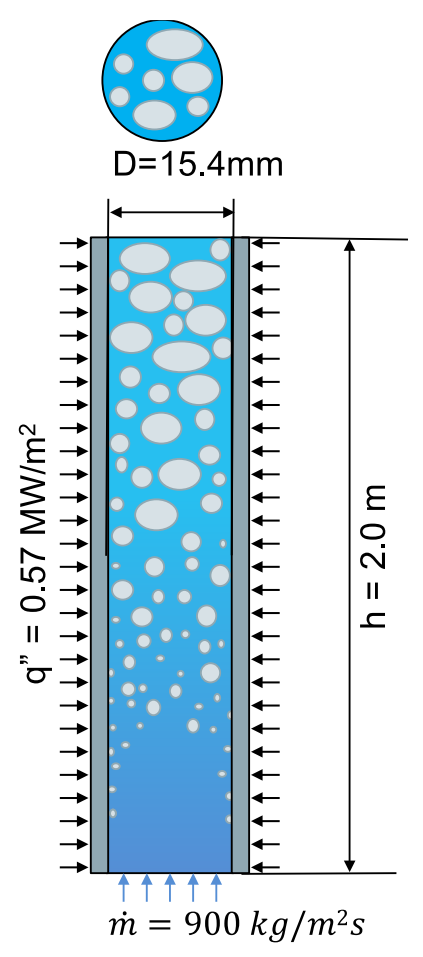

Figure 5-3. Channel characteristics for Bartolomei \& Chanturitya validation cases. 


\subsection{DEBORA (from Yao and Morel, 2004)}

- Data source:

- Reported in Yao and Morel, "Volumetric interfacial area prediction in upward bubbly two-phase flow," International Journal of Heat and Mass Transfer 47 (2004) 307-328.

- $\quad$ Related CASL challenge problems

$$
\text { - CRUD, DNB, BWR }
$$

- Coolant

$$
\text { - Boiling R12 refrigerant }
$$

- Flow Regime

$$
\text { - Bubbly }
$$

- Dimensions

- Pipe diameter $=0.0192 \mathrm{~m}$

- Channel length $=5 \mathrm{~m}$ (3.5 m heated $)$

- Conditions

- Wall heat flux $=73.89$ to $109.42 \mathrm{~kW} / \mathrm{m}^{2}$

- System pressure $=1.459$ to $2.617 \mathrm{MPa}$

- Inlet mass flux $=1986$ to $2981 \mathrm{~kg} / \mathrm{m}^{2} \mathrm{~s}$

- Inlet subcooling $=16.1^{\circ} \mathrm{K}$ to $23.2^{\circ} \mathrm{K}$

- Data

- Local void fraction

- Interfacial area concentration

- Interfacial velocity

- Sauter mean diameter

- Liquid velocity

- Turbulent intensity

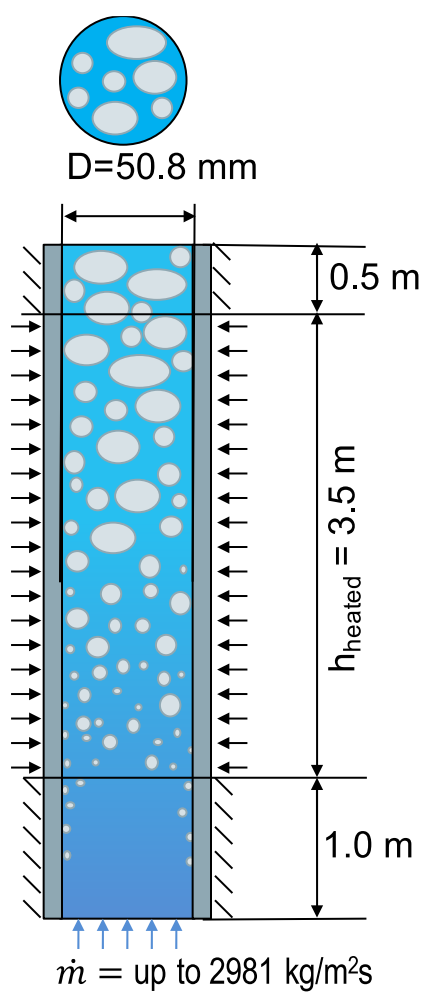

Figure 5-4. Channel characteristics for DEBORA validation cases. 


\subsection{PSBT Benchmark, Subchannel Cases}

- Data source:

- Rubin, A., et al. "OECD/NRC Benchmark based on NUPEC PWR subchannel and bundle tests (PSBT), Volume I:

Experimental Database and Final Problem Specifications." US NRC/OECD Nuclear Energy Agency Benchmark (2010).

- Related CASL challenge problems

- Coolant

- CRUD, DNB, BWR

- Boiling water

- Flow regime

- Bubbly

- Dimensions

- Considered 4 subchannel geometries

- Channel Width $=0.0157 \mathrm{~m}$

- "Rod" Diameter $=0.0126 \mathrm{~m}$

- Heated Channel length $=1.555 \mathrm{~m}$

- Conditions

- Test section power $=15$ to $80 \mathrm{~kW}$

- $\quad$ System pressure $=4.9$ to $16.6 \mathrm{MPa}$

- Inlet mass flux $=550$ to $4150 \mathrm{~kg} / \mathrm{m} 2 \mathrm{~s}$

- Inlet coolant temperature $=413$ to $618 \mathrm{~K}$

- Data

- Chordal void fraction

- CT void fraction
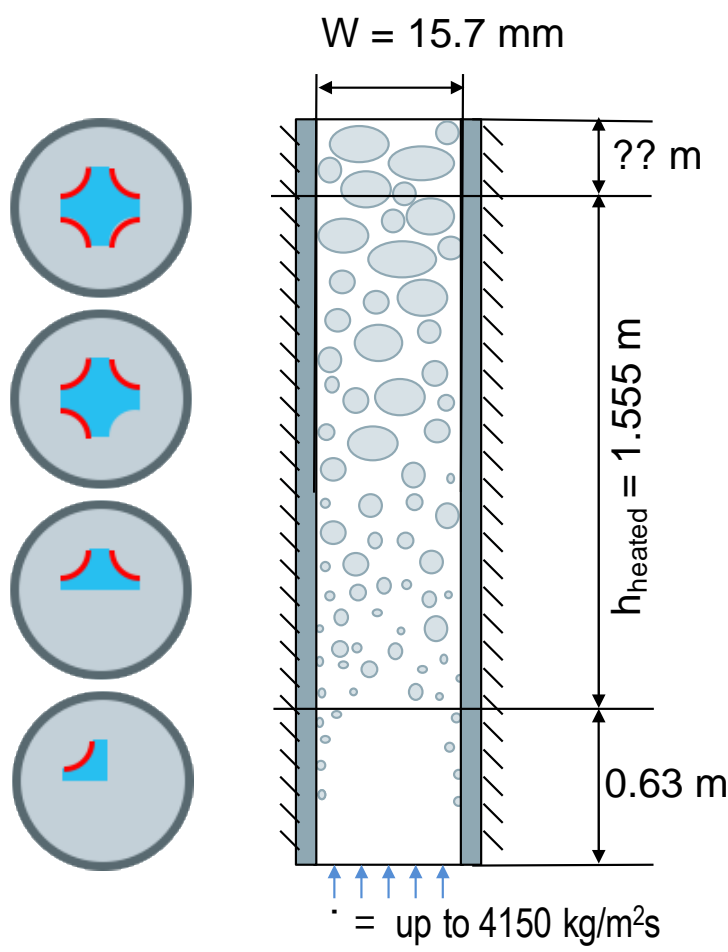

Figure 5-5. Channel characteristics for PSBT validation cases (four different subchannel cross sectional geometries considered are shown). 


\subsection{Weatherhead (1963)}

- Data sources:

- Weatherhead, R. J. "Nucleate Boiling Characteristics and The Critical Heat Flux Occurrence in Subcooled Axial-Flow Water Systems." ANL-6675, United States, (1963).

- Related CASL challenge problems

$$
\text { - DNB }
$$

- Coolant

$$
\text { - Boiling water }
$$

- Flow regime

- Bubbly, DNB

- Dimensions

- Pipe diameter $=0.0077 \mathrm{~m}$

- Channel length $=0.460 \mathrm{~m}$

- Conditions

- Wall heat flux $=$ up to $6.0 \mathrm{MW} / \mathrm{m}^{2}$

- System pressure $=13.8 \mathrm{MPa}$

- Inlet mass flux $=632$ to $2712 \mathrm{~kg} / \mathrm{m}^{2} \mathrm{~s}$

- Inlet subcooling $=10.46 \mathrm{~kJ} / \mathrm{kg}$ to $1.313 \mathrm{MJ} / \mathrm{kg}$

- Data

- Void profile

- Wall temperature profile

- Bulk temperature profile

- DNB

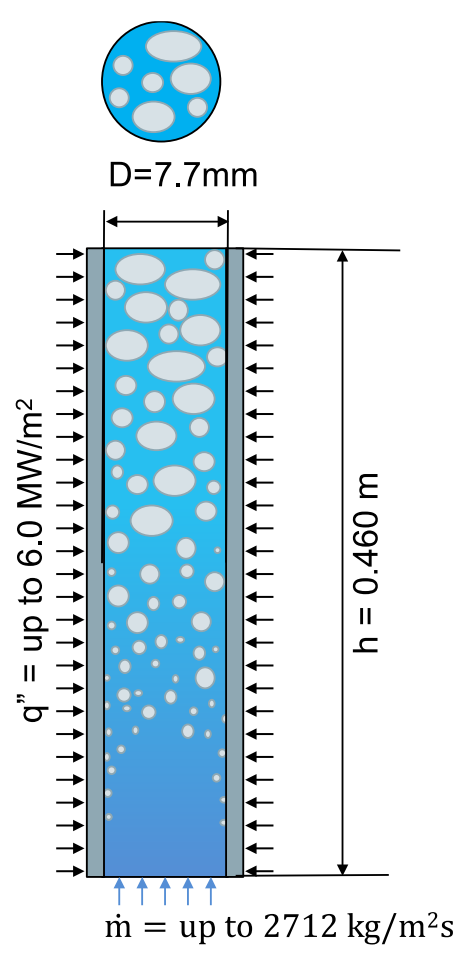

Figure 5-6. Channel characteristics for Weatherhead validation cases. 


\subsection{Adamsson and Anglart (2011)}

- Data sources:

- Adamsson, Carl, and Henryk Anglart. "A reinterpretation of measurements in developing annular two-phase flow." Nuclear Engineering and Design 241.11 (2011): 4562-4567.

- Adamsson, Carl. "Measurements of Film Flow Rate in Heated Tubes with Various Axial Power Distributions." KTH Royal Institute of Technology (2006).

- Related CASL challenge problems

- BWR

- Coolant

- Boiling R12 refrigerant

- Flow regime

$$
\text { - Annular }
$$

- Dimensions

- Pipe diameter $=0.014 \mathrm{~m}$

- Channel length $=3.65 \mathrm{~m}$

- Conditions

- Wall heat flux $=0.74-1.0 \mathrm{MW} / \mathrm{m}^{2}$

- System pressure $=7.0 \mathrm{MPa}$

- Inlet mass flux $=750-1450 \mathrm{~kg} / \mathrm{m} 2 \mathrm{~s}$

- Inlet subcooling $=10 \mathrm{~K}$

- Data

- Film flow rate

- Droplet flow rate

- Void fraction distribution

- Dryout 


\subsection{BFBT Benchmark}

- Data source:

- Neykov, D., et al. "NUPEC BWR Full-size Fine-mesh

Bundle Test (BFBT) Benchmark: Volume I:

Specifications." US NRC/OECD Nuclear Energy

Agency Benchmark (2005).

- Related CASL challenge problems

- BWR

- Coolant - boiling water

- Flow regime

- Bubbly, slug churn, annular

- Dimensions

- Channel box width $=0.1325 \mathrm{~m}$

- Rod configuration $=8 \times 8$

- Rod diameter $=0.0123 \mathrm{~m}$

- Rod pitch $=0.0162 \mathrm{~mm}$

- Heated channel length $=3.7 \mathrm{~m}$

- Conditions

- Test section power $=15$ to $80 \mathrm{~kW}$

- Axial power distribution = Uniform

- Radial power distribution = Map

- System pressure $=1.0$ to $8.6 \mathrm{MPa}$

- Inlet mass flow $=2.52$ to $17.64 \mathrm{~kg} / \mathrm{s}$

- Inlet subcooling $=20.9$ to $126 \mathrm{~kJ} / \mathrm{K}$

- Exit quality $=2 \%$ to $25 \%$

- Data

- Chordal void fraction

- CT void fraction

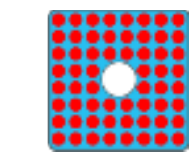

$\mathrm{W}=132.5 \mathrm{~mm}$

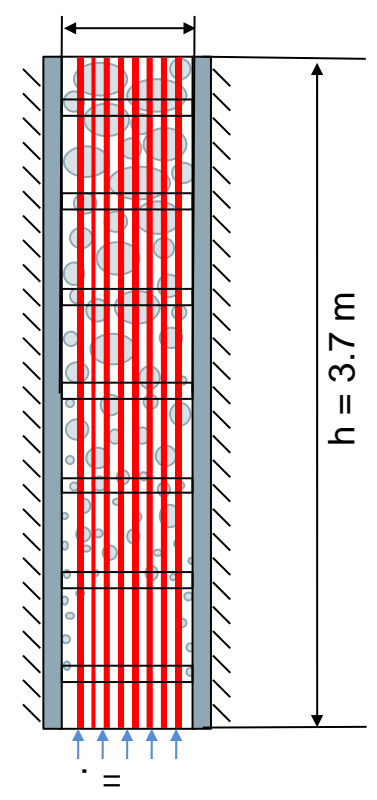

Figure 5-8. Channel characteristics for BFBT validation cases.

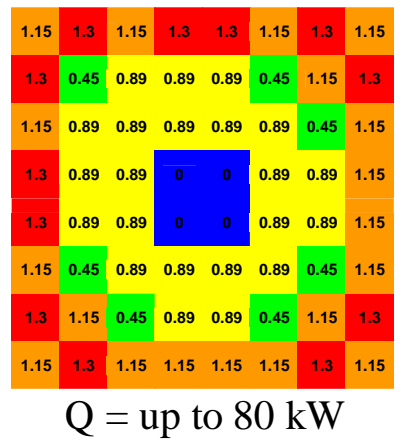

Figure 5-9. Radial power profile for BFBT validation cases. 


\subsection{V\&V Assessment Reporting}

The results of each validation assessment will be documented in a code validation assessment report to be updated at least annually. Each validation assessment will be described in a separate chapter, which includes, at a minimum, the following information:

- Code version

- Verification of code installation

- Description of validation experiment

- Description of methodology, including detailed descriptions of user coding and/or field functions implemented by the user

- Assessment criteria

- Simulation results

- Solution verification

- Assessment results

\section{ADDITIONAL CODES DEVELOPED OR USED BY CASL THM}

The CASL THM team develops capabilities in or makes use of insights gained from four unique CFD platforms. STAR-CCM+, a commercial CFD code that serves as the principal framework for model development, is a 2nd order diffusion-limited, SIMPLE-based finite volume formulation with a Eulerian-Eulerian multiphase boiling flow model. OpenFOAM, and particularly the EulerFOAM module, is an open source CFD code that provides a 2nd order diffusion-limited, PIMPLE-based finite volume formulation with a Eulerian-Eulerian multiphase flow model. OpenFOAM is used to support development of advanced data integration strategies which would be difficult to implement within the framework of a commercial software package. FCT3D is a specialized pressureprojection predictor-corrector solver that supports front tracking for identification of gas-liquid interfaces in direct numerical simulations of bubbly flows. PHASTA is a high order finite element solver with a multiphase level set method for identification of gas-liquid interfaces in direct numerical simulations of bubbly flows. FCT3D and PHASTA are used to enhance understanding of underlying physics and establish databases for demonstration of multi-scale data integration.

This plan only addresses $\mathrm{V} \& \mathrm{~V}$ of the advanced two-phase boiling capability developed within the framework of the STAR-CCM+ code. The other codes provide insight into underlying physics to support model development but are not expected to contribute directly to the solution of CASL challenge problems or the validation of the capabilities implemented in STAR-CCM+. As long as they do not contribute directly, $\mathrm{V} \& \mathrm{~V}$ practices are left to their individual developers. However, consistency with the requirements defined for STAR-CCM+ herein is desirable and recommended.

\section{ACKNOWLEDGEMENTS}

The author gratefully acknowledges the support of CD-adapco staff, especially Gary Gauvin, Director of Application Lifecycle Management, and Eric Volpenhein, Senior Account Manager, in the development of this $\mathrm{V} \& \mathrm{~V}$ plan. The author also gratefully acknowledges the support of the authors of the CASL V\&V plan, Dr. Vince Mousseau of Sandia National Laboratory and Prof. Nam Dinh of North Carolina State University, for their insightful comments and discussions as the V\&V plan was developed. 


\section{CONCLUSION}

This document defines V\&V plans for CASL multiphase boiling CFD models implemented within the commercial CFD code STAR-CCM+, developed by CD-adapco. This document defines or identifies documents which define expected practices for code version control, change management, code verification, solution verification, and model validation. This is a living documented that will be updated as additional verification tests and validation cases are adopted by the CASL THM development team.

\section{REFERENCES}

2008 ANSI Standard V\&V 20. ASME Guide on Verification and Validation in Computational Fluid Dynamics and Heat Transfer, 2009.

Mousseau, V, and Dinh, N., CASL Verification and Validation Plan, CASL-U-2016-116-000 (2016).

Sieger, M., CASL-QA-030 CASL Software Quality Assurance Requirements, CASL-U-2015-0010000 (2015).

Smith, T. M., et al., A Multi-Year Plan for Enhancing Turbulence Modeling in Hydra-TH, CASL-U2015-0085-000 (2015). 